\title{
Trabalho Experimental: Concepções e Práticas de Estagiários de Física e Química
}

\author{
ANA MARIA FREIRE *
}

O trabalho experimental começou a ser usado como estratégia de ensino, nas aulas de Química e de Física do ensino secundário, nos finais do século passado, após a Universidade de Harvard o ter introduzido como prova de acesso ao ensino superior (Hurd, 1969). Desde o século passado que os educadores científicos o consideram como actividade instrucional essencial nas aulas de ciências (Solomon, 1994). Todavia, a investigação cientifica conduzida com o objectivo de averiguar o tipo de aprendizagens proporcionadas com a realização do trabalho experimental nas aulas de ciências tem vindo a mostrar a sua pouca eficácia em promover a compreensão dos conceitos científicos embora se revele importante no desenvolvimento de competências laboratoriais e científicas (Clackson $\delta$ Wright, 1992). Com efeito, não existe consenso entre os investigadores acerca das finalidades do trabalho experimental e das aprendizagens que proporciona aos alunos (White, 1991). Várias posições emergem na literatura educacional acerca das finalidades do trabalho experimental, umas centradas nos alunos, outras na actividade do professor e, ainda outras, na ciência.

Lazarowitz e Tamir (1994) referem quatro finalidades associadas à utilização do trabalho experimental nas aulas de ciências, perspectivando-as em função dos alunos e da aprendizagem.

- Proporcionar meios e experiências concretas que possibilitem aos alunos confrontarem as suas concepções alternativas;

- Criar condições para a manipulação dos dados através do uso de microcomputadores;

- Possibilitar o desenvolvimento de competências de pensamento lógico, especialmente através de questões relacionadas com ciência, tecnologia e sociedade;

- Possibilitar a aquisição de valores científicos, especialmente aqueles relacionados com a natureza da ciência.
Ao contrário, Wellington (1994) expressa as finalidades associadas ao trabalho experimental em função do papel atribuído ao professor.

- Ilustrar acontecimentos ou fenómenos. (tais como reacções químicas, especialmente se os reagentes são caros, perigosos e se a experiência ocupa muito tempo para ser feita numa hora por todos os alunos);

- Transmitir conhecimento científico (conceitos, leis, princípios ou teorias);

- Motivar os alunos (aumentar a curiosidade, fascinar, entreter, interessar);

- Confrontar/desafiar os alunos (prever, observar, explicar)

Mais recentemente, Luneta (1998) considera outras finalidades, centradas na ciência, para a realização do trabalho experimental.

- Compreensão de conceitos científicos e da natureza da ciência

- Desenvolvimento de competências e atitudes científicas

- Promoção da investigação científica

\section{- Motivação dos alunos}

Os educadores em ciência parecem aceitar finalidades múltiplas para a realização do trabalho experimental, preconizando-lhe diferentes funções no processo de ensino/ aprendizagem. Reconhece-se, no entanto, que constitui tarefa difícil para os professores a consideração. em simultâneo, de todas as finalidades propostas. Com efeito, os professores atribuem diferentes prioridades às finalidades do trabalho experimental.

As prioridades atribuídas pelos professores às finalidades do trabalho experimental afectam o modo como o põem em acção na sala de aula (Hodson, 1993). Os professores que valorizam a aprendizagem de conceitos concentra-se-ão, certamente, em actividades experimentais que possibilitem aos alunos a aquisição do conhecimento científico através da obtenção da resposta correcta. Outros professores poderão dar mais ênfase ao desenvolvimento de competências científicas e sociais, emergindo o laboratório como o único meio onde se realizam essas aprendizagens, embora para outros possa constituir um entre vários meios possíveis (White, 1996).

Apesar de haver uma longa tradição no uso do trabalho experimental não existe consenso entre os professores sobre o modo de o organizar (Hodson, 1996a). Nesta última metade do século XX, o trabalho experimental foi perspectivado de modo diverso, nos currículos de ciências que foram emergindo. Nos anos 60 , os currículos pressupunham que os alunos aprendiam ciência, ao fazer ciência, através da descoberta e do inquérito científico, dando ênfase às dimensões substantiva e sintáctica da ciência Schwab (1978). Por um lado, valorizava-se a aprendizagem de conhecimento científico, por outro lado, o desenvolvimento de processos científicos. Todavia, para muitos alunos as tarefas experimentais realizadas no laboratório pouco contribuem para aprendizagens de ciência e sobre ciência (Hodson, 1998). Nos anos 80 e 90 , a orientação construtivista tornou-se proeminente, ao considerar a aprendizagem como um processo interpretativo conducente à compreensão da realidade (Marton, Dall'Alba \& Beaty, 1993). Assim, atribui-se aos alunos um papel activo no processo de aprendizagem de ciência através da criação de significados. O trabalho experimental pode constituir um meio que possibilita a construção de novos significados e a mudança conceptual, conduzindo ao abandono de concepções alternativas possuídas pelos alunos (Driver, 1994).

As possibilidades existentes para estruturar o trabalho experimental dependem das finalidades que se pretendem atingir com o ensino das ciências para todos os alunos. Todavia, aceitar múltiplas finalidades para o trabalho experimental é uma coisa; concordar acerca do modo de o implementar é outra. Os professores podem definir as mesmas finalidades para o trabalho experimental mas 
organizá-lo de modo diferente (Olsen, Hewson \& Lyons, 1996). Afigura-se, por isso, necessário conhecer o pensamento e o agir dos professos relativamente ao trabalho experimental.

Neste estudo, distingue-se demonstração experimental (DE) de trabalho experimental (TE). Entende-se por demonstração experimental (DE) as experiências realizadas pelo professor, com ou sem auxílio de alunos, na sala de aula ou no laboratório. No decorrer da demonstração experimental o professor desempenha o papel principal, quer a questionar e a informar os alunos, quer a realizar a experiência. Ao contrário, trabalho experimental (TE) refere-se, quer ao planeamento de experiências e investigações, quer à realização de experiências, pelos alunos em pequeno grupo, no laboratório ou na sala de aula. Os alunos desempenham o papel principal, ao interactuar com o material experimental para realizar as experiências que foram planeadas por eles ou pelo professor. Nas aulas de trabalho experimental, o professor encontra-se numa posição de supervisão apoiando o trabalho dos alunos e respondendo às suas solicitações.

O estudo que se apresenta a seguir insere-se num outro mais global que visa descrever mudanças nas concepções de ensino e na prática instrucional, de estagiários de Física e Química, durante o processo de aprender a ensinar vivenciado nos estágios pedagógicos, e identificar, também, a consistência entre concepções de ensino e prática instrucional. Com esta comunicação pretende-se (a) descrever as concepções dos estagiários de Física e Química acerca do trabalho experimental; (b) caracterizar o trabalho experimental posto em acção, pelos estagiários, em aulas observadas durante o ano de estágio pedagógico; (c) analisar a consistência entre concepções sobre trabalho experimental e o tipo de trabalho experimental usado nas aulas observadas durante o estágio pedagógico.

\section{METODOLOGIA}

A metodologia usada neste estudo tem as suas raízes em orientações de base naturalista (Lincoln \& Guba, 1985), interpretativa (Erickson, 1986) e construtivista (Guba \& Lincoln, 1994). Abordagens deste tipo têm sido largamente divulgadas e utilizadas, por vários investigadores, para a compreensão das situações de ensino partindo das acções dos professores na sala de aula (Elbaz, 1983; Clandinin, 1986).

\section{Participantes}

Participaram neste estudo catorze estagiários de Física e Química, durante o estágio pedagógico, no ano lectivo de 1994/95. Os nomes atribuídos aos estagiários são fictícios. No início do estágio pedagógico, foram explicadas as linhas gerais do trabalho a desenvolver e foi solicitada a colaboração de cada um dos estagiários. Concordaram em ser entrevistados, várias vezes, ao longo do ano e permitiram a observação das suas aulas. Foi estabelecido um calendário, quer para as entrevistas, quer para as assistências às aulas, com início em Outubro de 94 e fim em Maio de 95, que possibilitou a gravação de dezasseis aulas de cada estagiário. Os estagiários informaram os alunos que as aulas com observadores externos seriam objecto de audiogravação.

\section{Recolha de Dados}

Os dados utilizados, neste estudo, resultam da observação de aulas, com uso de dois tipos de registo notas de campo e audiogravação, e de entrevistas semi-estruturadas, conduzidas nas fases inicial e final do estágio pedagógico. As aulas audio- gravadas e as entrevistas foram depois transcritas e analisadas. Com efeito, os dados relativos às aulas foram recolhidos ao longo do ano lectivo e resultaram da assistência a 224 aulas de Física e Química leccionadas, pelos estagiários, a alunos do $8^{\circ}$ e $9^{\circ}$ anos do ensino básico. O Quadro 1 apresenta o número de aulas observadas por disciplina científica de ensino, ano do ensino básico, com especificação do número de aulas com trabalho experimental (TE).

A discrepância entre o número de aulas de Física (155) e de Química (69) observadas resulta dos planeamentos anuais realizados nos diferentes núcleos de estágio e reflectem o modo como os grupos disciplinares das diferentes escolas geriram o programa da disciplina. Neste ano lectivo, a reforma curricular já tinha atingido os alunos do $8^{\circ}$ ano, que seguiam o novo programa de Física e Química, enquanto que os alunos do $9^{\circ}$ ano cumpriam o programa anterior.

As entrevistas foram conduzidas, nas fases inicial e final do estágio pedagógico, com a finalidade de identificar as concepções de ensino dos estagiários e possibilitar a caracterização de mudanças nas concepções de ensino de ciências. Usou-se a entrevista sobre ocorrências já descrita anteriormente (Freire, 1991) para identificar as concepções dos estagiários acerca do trabalho experimental.

\section{Análise dos Dados}

O método analítico seguido, quer para a caracterização das actividades instrucionais usadas, quer para descrever as concepções sobre o trabalho experimental, baseou-se no

Quadro 1 - Aulas Observadas por Disciplina Científica de Ensino, Ano da Escolaridade e de Trabalho Experimental (TE)

\begin{tabular}{ccccccr}
\hline $\begin{array}{c}\text { Disciplina Científica } \\
\text { de Ensino }\end{array}$ & \multicolumn{2}{c}{$\begin{array}{c}\mathbf{8}^{\mathbf{0}} \text { Ano } \\
\text { Total --- Com TE }\end{array}$} & \multicolumn{2}{c}{$\begin{array}{c}\text { Total -- Com TE } \\
\mathbf{9}^{\mathbf{0}} \text { Ano }\end{array}$} & \multicolumn{2}{c}{$\begin{array}{c}\mathbf{8}^{\mathbf{0}} \mathbf{e} \mathbf{9}^{\mathbf{0}} \text { Anos } \\
\text { Total --. Com TE }\end{array}$} \\
\hline Física & 52 & 22 & 103 & 23 & 155 & 45 \\
\hline Química & 61 & 20 & 8 & 0 & 69 & 20 \\
\hline Total de Aulas & 113 & 42 & 111 & 23 & 224 & 65 \\
\hline
\end{tabular}


processo de comparação e questionamento constante dos dados, tal como é preconizado por Strauss e Corbin (1990). Em relação às aulas observadas, foram identificadas treze tipos de actividades instrucionais, exposição de matéria, questionamento e debate, leitura de textos, demonstração experimental, visionamento de filmes, trabalho de casa, trabalho experimental e tarefas tecnológicas, resolução de problemas, simulaçôes e trabalho de computador, apresentação de trabalhos, correcção de exercícios, avaliação dos alunos e funcionamento e convivência social.

Esta comunicação incide sobre a análise das aulas de Química onde foi observado a realização de trabalho experimental (TE). Para descrever diferentes tipos de trabalho experimental e caracterizar as tarefas experimentais realizadas pelos alunos nas aulas de Química, considerou-se o programa de acção que orienta as tarefas a realizar pelos alunos e o modo de organizar os alunos (Doyle, 1990). O trabalho experimental implementado tem subjacente um programa de acção a pôr em uso pelo professor, com a finalidade de promover aprendizagens, de ciência, sobre ciência e sobre o fazer ciência (Hodson, 1998). Nas aulas de trabalho experimental, os alunos foram organizados em grupo. O planeamento de experiências, a realização das experiência ou a comunicação de resultados, constituem tarefas a realizar pelos alunos, no decorrer deste tipo de aulas. Para caracterizar as tarefas experimentais, usadas nas aulas de Química, atende-se a três aspectos (a) papel dos alunos na escolha da tarefa, (b) estrutura atribuída, e (c) tipo de tarefa (Wellington, 1994).

O papel do aluno na definição da tarefa experimental pode variar entre duas posições extremas, de activo a passivo. No primeiro caso, o aluno é envolvido na escolha das questões a investigar e do material a usar sem que o professor ponha restrições às escolhas efectuadas. No segundo caso, é o professor a colocar as questões de investigação, limitan- do-se os alunos a encontrar as respostas pretendidas utilizando o material experimental que foi escolhido pelo professor. Com efeito, a responsabilidade dos alunos na escolha do tipo de tarefa experimental a realizar é diversificada. Alguns professores dão mais autonomia do que outros, aos alunos.

Relativamente à estrutura, a tarefa experimental varia ao longo de um continuum, desde muito estruturada, com a especificação de todos os passos a seguir durante a execução da experiência até pouco estruturada ou mesmo sem estrutura em que não são dadas orientações para a realização da tarefa, devendo os alunos encontrar uma resposta para o problema colocado. No primeiro caso, os alunos aprendem a seguir as directrizes dadas pelos professor, quer por escrito, quer oralmente. No segundo caso, os alunos podem escolher o caminho que acharem mais conveniente para responder à questão de investigação, independentemente de quem a formulou.

O tipo de tarefa experimental a realizar pode ser fechada ou aberta, conforme corresponder a uma única solução ou a várias soluções possíveis. Tarefa experimental aberta significa que muitas soluções são igualmente aceitáveis, com muitos caminhos, não existindo uma única resposta correcta, mas sim, várias possíveis. Tarefa experimental fechada significa que existe somente uma única solução e um único caminho para o problema.

Para além destes aspectos, importa também salientar o papel da teoria nestas aulas de trabalho experimental. De acordo com Olsen, Hewson, Lyons (1996), existe um corpo de conhecimentos acerca do mundo natural, normalmente expresso sob a forma de leis e princípios, que tem sido progressivamente desenvolvido ao longo dos tempos através de processos científicos. Este conhecimento é aceite como a "verdade" acerca do mundo. Faz parte da cultura a ser transmitida de geração a geração. $O$ conhecimento científico é traduzido em proposiçōes que os alunos devem aceitar e aprender. $\mathrm{O}$ trabalho experimental pode ajudar à aquisição deste corpo de conhecimentos, embora possa desempenhar outra função. Por um lado, o trabalho experimental pode envolver a realização de experiências que têm por objectivo a recolha de dados que possibilitam a verificação de leis e teorias. Por outro lado, o trabalho experimental pode ser visto como meio que fomenta o espírito da investigação científica entre os alunos, permitindo-lhes descobrir "coisas" por si próprios, de modo a identificar regularidades e estabelecer leis e teorias (Luneta, 1998).

A análise das entrevistas permitiu identificar os argumentos usados pelos estagiários para justificar a utilização de trabalho experimental nas aulas de Física e Química. As categorias de análise emergiram da entrevista sobre ocorrências. Atendeu-se (a) à relação com a teoria, (b) ao modo de organizar o trabalho experimental, (c) aos inconvenientes associados com a realização de trabalho experimental e (d) as vantagens associadas à realização do trabalho experimental. Nesta comunicação considera-se que existe consistência entre concepções acerca do trabalho experimental e o tipo de trabalho experimental posto em uso nas aulas de química observadas quando os argumentos usados nas entrevistas especificam o tipo de tarefas experimentais realizadas pelos alunos.

\section{Resultados}

Organiza-se a apresentação dos resultados em função dos objectivos especificados anteriormente.

- Descrever as concepções dos estagiários de Física e Química acerca do trabalho experimental;

- Caracterizar o trabalho experimental posto em acção, pelos estagiários, nas aulas observadas durante o ano de estágio pedagógico;

- Analisar a consistência entre concepções e prática instrucional. 


\section{Descrição das concepções dos estagiários acerca do traba- lho experimental}

As concepções salientadas pelos estagiários acerca da utilização do trabalho experimental nas aulas de Física e Química leccionadas a alunos do ensino básico foram muito diversificadas. Os estagiários referiram (a) aprendizagem da teoria, (b) aprendizagem dos processos da ciência, (c) aprender a fazer ciência, (d) adequação aos alunos, (e) restrições à utilização do trabalho experimental, e (f) modos de organizar o trabalho experimental. Apresenta-se no Quadro 2, as concepções dos estagiários acerca da utilização do trabalho experimental. Na segunda coluna, colocou-se dentro de parênteses a letra E seguida de um número o que permite referenciar o estagiário que expressou o argumento acerca do trabalho experimental.
Os estagiários salientaram concepções diversificadas relativamente ao papel do trabalho experimental na aprendizagem da teoria. O Quadro 2 mostra que alguns estagiários (7) referiram como função principal do trabalho experimental a verificação e aplicação da teoria. Ao contrário, a "aprendizagem de conceitos", a "consolidação e compreensão da teoria" e a "ilustração daquilo que o professor diz" foi referido por um número restrito de estagiários. A aprendizagem de processos científicos e o desenvolvimento de competências científicas somente foi salientado por dois estagiários. Relativamente ao envolvimento dos alunos na resolução de problemas e na investigação científica somente foi abordado por um estagiário (E2) ao consisderar que o "trabalho experimental permite aos alunos encontrarem em grupo a solução para o problema e procurarem uma explicação". O modo de organizar o traba- lho experimental foi salientado por onze estagiários embora revelando posições antagónicas. Alguns estagiários (6) referiram a necessidade de orientar o trabalho experimental através da utilização de um guião, por várias razões: obrigar os alunos a encontrar resposta ao problema formulado, possibilitar o atingir dos objectivos propostos, permitir a realização de aprendizagens e orientar o trabalho dos alunos. Somente dois estagiários se manifestaram a favor da utilização de trabalho experimental sem orientação ou orientado para a descoberta por obrigar os alunos a pensar e a trabalhar e permitir a realização de aprendizagens. Ao contrário, cinco estagiários, criticaram o trabalho experimental sem guião e orientado para a descoberta por várias razões. Consideraram que não permite integrar o conhecimento a adquirir com aquele que já possuem, não é adequado aos alunos, não promove aprendizagens,

Quadro 2 - Concepções Relativas à Utilização de Trabalho Experimental em Aulas de Física e Química para Alunos do Ensino Básico

\begin{tabular}{|c|c|}
\hline Categorias de Análise & Argumentos Salientados pelos Estagiários \\
\hline Aprender teoria & $\begin{array}{l}\text { - Consolidar e compreender a teoria (E1) } \\
\text { - Ilustrar aquilo que o professor diz (E1, E8) } \\
\text { - Aprender conceitos (E2) } \\
\text { - Verificação e aplicação da teoria (E6, E8,E10, E11, E12, E13, E14) }\end{array}$ \\
\hline $\begin{array}{l}\text { Aprender os processos } \\
\text { da ciências }\end{array}$ & $\begin{array}{l}\text { - TE permite observar e formular um problema (E3) } \\
\text { - TE para desenvolver capacidades e habilidades (E12) }\end{array}$ \\
\hline Aprender a fazer ciência & - TE para os alunos encontrarem em grupo a solução para o problema e procurarem uma explicação (E2) \\
\hline $\begin{array}{l}\text { Modo de organizar } \\
\text { o trabalho experimental }\end{array}$ & $\begin{array}{l}\text { - TE sem guico obriga os alunos a pensar e a trabalhar (E1) } \\
\text { - TE com guião e objectivos a atingir proporciona aos alunos encontrarem a solução para o problema } \\
\text { formulado (E2) } \\
\text { - TE orientado para os alunos atingirem os objectivos (E5) } \\
\text { - TE centrado na descoberta não permite os alunos integrarem os conhecimentos a adquirir com } \\
\text { aqueles que já possuíam (E5) } \\
\text { - TE sem guião e sem orientação do professor não é adequado aos alunos por não promover aprendizagens (E6) } \\
\text { - TE orientado para os alunos não se afastarem dos objectivos em virtude do elevado número de alunos } \\
\text { por turma (E6) } \\
\text { - TE orientado para a descoberta permite a realização de aprendizagens (E7) } \\
\text { - TE com guião e orientado pelo professor possibilita aprendizagens (E8, E9) } \\
\text { - TE sem guião e sem orientação do professor poderá não promover aprendizagens (E10) } \\
\text { - TE com guião para orientar o trabalho dos alunos (E11) } \\
\text { - TE centrado na descoberta pode levar os alunos a ficar com conceitos errados (E12) } \\
\text { - TE centrado na descoberta e sem guião levanta dificuldades aos alunos (E14) }\end{array}$ \\
\hline Adequação aos alunos & $\begin{array}{l}\text { - TE nem sempre é adequado aos alunos (E5) } \\
\text { - TE muito dirigido não é adequado aos alunos (E7) } \\
\text { - TE sem guião e sem orientação do professor poderá ser adequado para uns alunos e não ser para outros (E10) } \\
\text { - TE para os alunos investigarem não é indicado para os alunos da escolaridade obrigatória (E13) }\end{array}$ \\
\hline $\begin{array}{l}\text { Restrições à utilização } \\
\text { do trabalho experimental }\end{array}$ & $\begin{array}{l}\text { - TE sempre que se justifique e que a escola tenha material suficiente (E10) } \\
\text { - TE sempre que exista tempo disponível para o realizar (E11) } \\
\text { - TE como investigação ocupa muito tempo (E13) }\end{array}$ \\
\hline
\end{tabular}


podem ficar com conceitos errados e levanta dificuldades aos alunos. Estes argumentos parecem ter subjacente a ideia que o trabalho experimental possibilita a aprendizagem da teoria, que poderá não ser promovida através da descoberta ou de tarefas experimentais não orientadas. Relativamente à adequação aos alunos, um estagiário considerou não ser adequado aos alunos, outro salientou que é adequado para uns e não é para outros. Dois estagiários salientaram ideias contrastantes, um deles considerou que o trabalho experimental muito dirigido não é adequado aos alunos (E7) enquanto que o outro estagiário (E13) referiu que trabalho experimental orientado para a investigação não é adequado aos alunos do ensino básico. Em relação a restrições à sua utilização, três estagiários fizeram referências. Um deles salientou como impedimento a falta de material experimental na escola, enquanto que os outros dois mencionaram falta de tempo.

Caracterização do Trabalho Experimental Usado pelos Estagiários em Aulas de Química

O trabalho experimental foi usado de modo diversificado pelos estagiários. Das 224 aulas observadas entre Outubro de 94 e Maio de 95. somente em 65 , houve realização de trabalho experimental, com diferente ocupação do tempo lectivo. Todavia, o trabalho experimental em aulas de Química foi observado em 20 aulas, leccionadas aos alunos do $8^{\circ}$ ano. Apresenta-se no Quadro 3, as características das tarefas experimentais realizadas pelos alunos, durante estas aulas de trabalho experimental.
O trabalho experimental foi implementado pelos estagiários de modo diversificado. Dois estagiários (E6 e E13) não usaram trabalho experimental nas aulas de Química observadas durante o ano lectivo enquanto que o estagiário E10 usou em três aulas. A duração média das tarefas experimentais realizadas pelos alunos foi de $28 \mathrm{~min}$, com o valor máximo de 48 min (E3) e o valor mínimo 9 min (E9). Para alguns estagiários as tarefas experimentais tiveram a duração da quase totalidade do tempo disponível para a aula (E3, E4, E5, E7 e E12) enquanto que para outros somente ocupou uma parte (E1, E2, E8, E9, E10, E11 e E14). Relativamente à escolha da tarefa, o estagiário designado por E7 permitiu que os seus alunos decidissem em grupo sobre a questão a investigar, numa aula de

Quadro 3 - Características das Tarefas Experimentais Realizadas pelos Alunos

\begin{tabular}{|c|c|c|c|c|c|c|c|c|}
\hline Estagiários & $\begin{array}{c}\text { DT } \\
(\min )\end{array}$ & $\begin{array}{c}\text { Dp } \\
\text { Dp (min) }\end{array}$ & $\begin{array}{c}\text { IT } \\
\text { IT }\left(n^{\circ} \mathrm{O}\right)\end{array}$ & $\begin{array}{c}\text { Ip } \\
\text { Ip }\left(n^{\circ} O\right)\end{array}$ & $\begin{array}{l}\text { Escolha } \\
\text { da tarefa }\end{array}$ & $\begin{array}{c}\text { Estrutura } \\
\text { tarefa }\end{array}$ & $\begin{array}{c}\text { Tipo } \\
\text { tarefa }\end{array}$ & $\begin{array}{c}\text { Relação } \\
\text { com a teoria }\end{array}$ \\
\hline E1 & 114 & 27 & 5 & 2 & $\begin{array}{l}\text { Passivo } \\
\text { Passivo }\end{array}$ & $\begin{array}{l}\text { Com guião } \\
\text { Sem guião }\end{array}$ & $\begin{array}{l}\text { Fechada } \\
\text { Fechada }\end{array}$ & $\begin{array}{l}\text { Aplic. Teoria } \\
\text { Aplic. Teoria }\end{array}$ \\
\hline E2 & 159 & 31 & 6 & 2 & $\begin{array}{l}\text { Passivo } \\
\text { Passivo }\end{array}$ & $\begin{array}{l}\text { Com guião } \\
\text { Sem guião }\end{array}$ & $\begin{array}{l}\text { Fechada } \\
\text { Fechada }\end{array}$ & $\begin{array}{l}\text { Aplic. Teoria } \\
\text { Aplic. Teoria }\end{array}$ \\
\hline E3 & 256 & 48 & 7 & 1 & Passivo & Sem guião & Aberta & Investigação \\
\hline E4 & 223 & 78 & 6 & 2 & $\begin{array}{l}\text { Passivo } \\
\text { Passivo }\end{array}$ & $\begin{array}{l}\text { Com guião } \\
\text { Sem guião }\end{array}$ & $\begin{array}{l}\text { Fechada } \\
\text { Aberta }\end{array}$ & $\begin{array}{l}\text { Aplic. Teoria } \\
\text { Investigação }\end{array}$ \\
\hline E5 & 121 & 42 & 3 & 1 & Passivo & Com guião & Fechada & Aplic. Teoria \\
\hline E6 & 90 & 0 & 3 & 0 & - & - & - & - \\
\hline E7 & 285 & 88 & 7 & 2 & $\begin{array}{r}\text { Passivo } \\
\text { Activo }\end{array}$ & $\begin{array}{l}\text { Com guião } \\
\text { Sem guião }\end{array}$ & $\begin{array}{l}\text { Fechada } \\
\text { Aberta }\end{array}$ & $\begin{array}{l}\text { Aplic. Teoria } \\
\text { Investigação }\end{array}$ \\
\hline E8 & 176 & 44 & 7 & 2 & $\begin{array}{l}\text { Passivo } \\
\text { Passivo }\end{array}$ & $\begin{array}{l}\text { Com guião } \\
\text { Com guião }\end{array}$ & $\begin{array}{l}\text { Fechada } \\
\text { Fechada }\end{array}$ & $\begin{array}{c}\text { Aquis. Técnica } \\
\text { Aplic. Teoria }\end{array}$ \\
\hline E9 & 46 & 9 & 2 & 1 & Passivo & Com guião & Fechada & Aplic. Teoria \\
\hline E10 & 222 & 103 & 6 & 3 & $\begin{array}{l}\text { Passivo } \\
\text { Passivo }\end{array}$ & $\begin{array}{l}\text { Com guião } \\
\text { Com guião }\end{array}$ & $\begin{array}{l}\text { Fechada } \\
\text { Fechada }\end{array}$ & $\begin{array}{l}\text { Aplic. Teoria } \\
\text { Aplic. Teoria }\end{array}$ \\
\hline E11 & 51 & 10 & 2 & 1 & Passivo & Com guião & Fechada & Aplic. Teoria \\
\hline E12 & 96 & 42 & 4 & 1 & Passivo & Com guião & Fechada & Aplic. Teoria \\
\hline E13 & 56 & 0 & 3 & 0 & - & - & - & - \\
\hline E14 & 89 & 39 & 4 & 2 & $\begin{array}{l}\text { Passivo } \\
\text { Passivo }\end{array}$ & $\begin{array}{l}\text { Com guião } \\
\text { Com guião }\end{array}$ & $\begin{array}{l}\text { Fechada } \\
\text { Fechada }\end{array}$ & $\begin{array}{l}\text { Aquis. Técnica } \\
\text { Aplic. Teoria }\end{array}$ \\
\hline Total & 1984 & 561 & 65 & 20 & $\begin{array}{c}\text { Passivo } 18 \\
\text { Activo } 1\end{array}$ & $\begin{array}{l}\text { Com guião } 14 \\
\text { Sem guião } 5\end{array}$ & $\begin{array}{c}\text { Fechada } 16 \\
\text { Aberta } 3\end{array}$ & $\begin{array}{c}\text { Aplic. Teoria } 14 \\
\text { Investigação } 3 \\
\text { Aquis. Técnica } 2\end{array}$ \\
\hline
\end{tabular}


trabalho experimental observada durante a leccionação da unidade Ácidos e Bases. O estagiário, no início da aula, começou por perguntar aos alunos: "o que gostariam de conhecer acerca dos ácidos e bases?" Informou seguidamente os alunos que podiam utilizar os livros que tinham à disposição para decidir sobre a questão a investigar. Todos os outros estagiários escolheram as tarefas experimentais a realizar pelos alunos na sala de aula, por isso, os seus alunos desempenharam um papel passivo em relação à escolha da tarefa. Em relação à estrutura da tarefa, três estagiários (E3, E4 e E7) realizaram aulas de trabalho experimental, sem a utilização de protocolo experimental, criando condições para a investigação. Todos os outros estagiários usaram um guião experimental para orientar as tarefas a desenvolver pelos alunos. Para a maioria dos estagiários, as tarefas experimentais eram fechadas, pois guiavam os alunos para a resposta correcta. Os estagiários E3, E4 e E7, ao organizarem as tarefas experimentais sem guião, mostraram-se abertos à diversidade de respostas encontradas pelos alunos. Com efeito, estes estagiários envolveram os alunos na realização de tarefas experimentais orientadas para a investigação cientifica, pedindo aos alunos para encontrar explicações para os fenómenos estudados. Neste sentido, pretendiam que a teoria emergisse da prática. Ao contrário, os outros estagiários (E1, E2, E5, E8, E9, E10, E11, E12 e E14), ao re- alizar as tarefas experimentais visavam a aplicação da teoria. O estagiário El usou os resultados experimentais obtidos pelos alunos para transmitir a teoria. Os estagiários E8 e E14 usaram tarefas experimentais que tinham como finalidade a aquisição de técnicas experimentais, como as técnicas elementares de analise. O tipo de tarefas experimentais usadas pelos estagiários parecem consistentes com as ideias salientadas acerca da utilização do trabalho experimental nas aulas de Química e Física.

Consistência entre Concepções sobre a Utilização do Trabalho Experimental e Tipo de Trabalho Experimental Implementado

Os resultados parecem sugerir a existência de consistência entre as concepções salientadas acerca do trabalho experimental e o modo como o trabalho experimental foi usado. Descreve-se para quatro estagiários (E1, E3, E5 e E9) o modo como o trabalho experimental foi implementado nas aulas de Química observadas e apresentam-se os argumentos usados pelos estagiários para justificar a realização do trabalho experimental. O Quadro 4 apresenta os argumentos referidos por estes estagiários para justificar o uso de trabalho experimental, nas aulas de Física e Química, e também o tipo de trabalho experimental usado, nas aulas observadas.
Maria do Carmo (El) evidenciou alterações relativamente ao modo de pensar o trabalho experimental. $\mathrm{Na}$ fase final do estágio pedagógico, omitiu referências ao trabalho experimental como modo "de ilustrar aquilo que o professor diz e de consolidar a teoria". Em contrapartida, salientou que o "trabalho experimental deve ser usado com guião restrito para obrigar os alunos a pensar", o que sugere mudança no modo de pensar o trabalho experimental. Na segunda parte do estágio pedagógico, Maria do Carmo realizou trabalho experimental sem transmitir previamente conhecimentos científicos aos alunos, reflectindo um modo distinto de organizar o trabalho experimental. Pelo contrário, numa aula de Química, para o $8^{\circ}$ ano, na primeira parte do ano lectivo, utilizou os resultados obtidos pelos alunos para transmitir o conhecimento científico.

Júlia (E3) orientou as aulas de trabalho experimental para a investigação científica. Numa aula de trabalho experimental, no domínio da Química, para o $8^{\circ}$ ano, os alunos usaram indicadores caseiros para identificar o caracter químico de um conjunto de soluções mistério. Júlia colocou-os perante uma situação problemática, ao pedir para eles resolverem o problema do Sr. Silva que tinha perdido o rótulo dos comprimidos e não sabia qual os que deveria tomar para combater a azia. No decurso da aula, deslocou-se a todas as bancadas sem fornecer in-

Quadro 4 - Consistência entre Concepções sobre Trabalho Experimental e Tipo de Trabalho Experimental Implementado

\begin{tabular}{|c|c|c|}
\hline Estagiários & Argumentos Referidos & Tipo de Trabalho Experimental \\
\hline E1 & $\begin{array}{l}\text {-TE para os alunos consolidarem e compreenderem a teoria } \\
\text {-TE para ilustrar aquilo que o professor diz } \\
\text {-TE sem guião obriga os alunos a pensar e a trabalhar }\end{array}$ & $\begin{array}{l}\text { - Com guião e fechado como aplicação da teoria. } \\
\text { - Serviu-se dos resultados experimentais para transmitir a teoria }\end{array}$ \\
\hline E3 & - TE permite observar e formular um problema & $\begin{array}{l}\text { - Sem guião e aberto criando condições para a realização } \\
\text { de investigação }\end{array}$ \\
\hline E5 & $\begin{array}{l}\text {-TE nem sempre é adequado } \\
\text {-TE tem de ser orientado para os alunos atingirem os objectivos } \\
\text {-TE centrado na descoberta nıo permite os alunos integrarem } \\
\text { os conhecimentos a adquirir com aqueles que já possuíam }\end{array}$ & - Com guião e fechado, como aplicação da teoria \\
\hline E9 & $\begin{array}{l}\text { - TE com guião e orientado pelo professor } \\
\text { possibilita aprendizagens }\end{array}$ & - Com guião e fechado, como aplicação da teoria \\
\hline
\end{tabular}


formação factual aos alunos que, por vezes, solicitavam a sua atenção.

\section{A - Está certo?}

P- Pergunta ao teu colega. Qual é o consenso no grupo?

A - já somos dois a achar.

(10 Aula observada, Química, 2/2/95)

A - Stora isto não dá. Qual é a cor?

$\mathrm{P}$ - Por que hei-de saber a cor e vocês não?

A - A Stora já tem muitos anos disto. P - Vocês têm de adquirir sensibilidade

(10 $0^{\mathrm{a}}$ Aula observada, Química, 2/2/95)

Em situação pós-activa do ensino revelou as dificuldades que tinha sentido no planeamento da aula. Comentou que não tinha sido fácil pôr a aula em prática por dificuldades de uso do laboratório para a preparação das soluções e por alguma falta de material. A opção por usar uma grande quantidade de soluções foi uma consequência da receptividade dos alunos em trazer materiais do dia a dia para analisar o carácter químico (Comentário escrito sobre a aula, 2/2/95).

A escolha da estratégia derivou do interesse dos miúdos em trabalhar e descobrir o pH das soluções e, também, pelo facto de poder facilitar a compreensão deste conceito e, nomeadamente, por desenvolver algumas capacidades de manuseamento, registo, interpretação e critica de resultados (Comentário escrito sobre a aula, 2/2/95).

Pretendia dar a maior autonomia aos alunos e realmente foi de tal forma que todos trabalharam no intervalo por sua própria iniciativa sem que tivesse dado conta (Comentário escrito sobre a aula, 2/2/95).

Os alunos só iam ter comigo quando já tinham acabado o trabalho ou quando não havia entendimento quanto às cores das soluções com os indicadores e aí funcionava a crença enraízada de que o que o professor disser está certo (Comentário escrito sobre a aula, 2/2/95).
Este tipo de actividades desenvolvidas à volta dos conteúdos são importantes para desenvolver uma gama de competências e atitudes de cooperação, autonomia, espírito crítico e auto-estima (Comentário escrito sobre a aula, 2/2/95).

Foi gratificante ver a atitude extremamente madura dos alunos, em grupo, a discutir, cada um com os seus argumentos para escolher o material mais adequado e o procedimento mais correcto (Comentário escrito sobre a aula, 2/2/95).

Nas aulas de trabalho experimental, privilegiou a investigação científica não só pelos processos científicos que podem ser desenvolvidos mas também pelos conceitos que podem ser aprendidos. Do pensamento acerca da acção importa reter os seguintes aspectos:

- A realização de trabalho experimental pode ser dificultada pela falta de material experimental e pela ocupação do laboratório;

- Trabalho experimental facilita a compreensāo de conceitos científicos;

- Trabalho experimental permite o desenvolvimento de processos científicos;

- Trabalho experimental como meio de promover a investigação cientifica;

- Trabalho experimental dá autonomia aos alunos; $\mathrm{e}$

- Trabalho experimental em grupo permite aos alunos confrontarem e discutirem entre si as suas ideias.

Nos argumentos expressos, nas fases inicial e final, não se deteve a fazer considerações sobre o trabalho experimental. Todavia, ressaltou, no final do ano lectivo, a importância de promover a investigação científica, de transmitir uma perspectiva científica aos alunos, de desenvolver processos científicos e de criar situações para os alunos aprenderem a trocar opiniões e a respeitar as opiniões dos colegas. As finalidades salientadas para o uso do trabalho experimental, em situação pós-activa, parecem ser consistentes com argumentos expressos relativamente ao ensino e à aprendizagem da ciência. Este posicionamento decorre do comentário escrito sobre uma aula de trabalho experimental, no qual Júlia evidencia o argumento referente ao desenvolvimento de competências científicas.

Daniel, numa aula de Química, da unidade Transformações Químicas, para alunos do $8^{\circ}$ ano, utilizou um guião experimental que adaptou do livro de texto em uso. O guião experimental orientava os alunos para as tarefas que tinham de desenvolver explicitando cada passo que deveriam seguir. Este modo de organizar o trabalho experimental parece consistente com a argumentação referida na fase final do estágio pedagógico que "o trabalho experimental tem de ser orientado para os alunos atingirem os objectivos". Daniel, na primeira parte do estágio pedagógico, durante uma aula de trabalho experimental para alunos do $9^{\circ}$ ano de Física, vivenciou uma experiência infeliz. Para essa aula, tinha planeado uma tarefa orientada para a descoberta. Os alunos não aderiram à proposta, não conseguiram resolver a questão e a aula de laboratório transformou-se num caos, com muitíssimas solicitações dos alunos. No final do ano lectivo, Daniel salientou "que o trabalho experimental orientado para a descoberta não permite integrar os conhecimentos adquiridos com aqueles já possuídos". Este argumento parece traduzir a experiência vivida, fase inicial do estágio pedagógico, na primeira aula observada com trabalho experimental.

Sérgio, numa aula de Química, para alunos do $8^{\circ}$ ano, planeou duas tarefas experimentais com o objectivo de levar os alunos a observar transformações químicas por junção de duas substâncias. Além disto, pretendeu servir-se dos resultados experimentais para introduzir os termos reacção química, reagentes e produtos. A primeira tarefa envolveu, numa primeira fase, a junção de água ao sulfato de cobre anidro e, numa segunda, a colocação de palha de aço no copo onde se encontrava o sulfato de cobre anidro e 
a água. Na segunda tarefa, os alunos misturaram água à cal que colocaram, previamente, num copo de precipitação. Para além disto, solicitou aos alunos que colocassem a mão na parede lateral do copo para sentir um aumento da temperatura. As tarefas experimentais foram realizadas muito rapidamente o que levou Sérgio a mudar de actividade instrucional e começar a expor matéria, introduzindo o significado de reaç̧ão química, reagentes e produtos. Ao comentar em citação pós-activa esta aula salientou que "quando testou as experiências seleccionadas constatou que o óxido de cálcio não estava nas melhores condições para ser utilizado. Sendo assim a aula em termos experimentais ficou mais pobre, permitindo que os alunos desligassem pois o que estavam a realizar não era deveras interessante" (Comentário escrito sobre a aula, $6 / 2 / 1995)$. Reconheceu que o óxido de cálcio não estava em boas condições para ser usado mas, mesmo assim, utilizou-o na aula, e que as experiências não eram muito interessantes mas, mesmo assim, seleccionou-as. Apesar de se ter apercebido dos problemas com que se ia deparar na sala de aula, nada fez para mudar. Referiu em situação pós-activa que "se leccionasse de novo esta aula tentaria alterar acima de tudo a sua forma recorrendo a experiências mais motivantes e de mais fácil interpretação por parte dos alunos" (Comentário escrito sobre a aula, 6/2/1995).

Sérgio não fez aulas de trabalho experimental muito atraentes para os alunos e não seleccionou as experiências mais adequadas aos seus alunos. No final do ano lectivo, referiu a necessidade do professor "promover a realização de trabalho experimental nas aulas", "planear aulas com material adequado aos alunos" e que "trabalho experimental com guião e orientado pelo professor possibilita aprendizagens". Esta argumentação parece reflectir aprendizagens realizadas sobre a utilização do trabalho experimental decorrentes de vivências não muito agradáveis e apontam para mudanças a introduzir, no futuro, na prática instrucio- nal. Com efeito, as aulas de trabalho experimental observadas não foram eficientes na promoção de aprendizagens. A análise parece sugerir consistência entre o que disse acerca do modo de aprender dos alunos e o modo de organizar o trabalho experimental e o modo como o implementou nas aulas observadas.

\section{DISCUSSÃO}

Este estudo revelou, quer diferentes concepções acerca da utilização do trabalho experimental, quer diferentes modos de o organizar na sala de aula. Evidenciou também consistência entre concepções acerca do trabalho experimental e o modo de implementação na sala de aula. Os argumentos que os estagiários usaram para justificar a realização do trabalho experimental foram diversificados. Alguns estagiários salientaram o trabalho experimental como um modo de ilustrar a teoria. Esta concepção associada ao uso do trabalho experimental parece traduzir ideias que prevaleciam em meados do século passado, acerca das finalidades associadas ao uso do trabalho experimental. Outros estagiários referiram o desenvolvimento de competências científicas e valorizaram a investigação científica nas aulas de ciência. Estas ideias associadas ao trabalho experimental parecem estar em sintonia com perspectivas recentes sobre finalidades do trabalho experimental que dá ênfase ao fazer ciência e ao envolvimento dos alunos na investigação científica e na resolução de problemas (Hodson, 1996b), embora tivesse sido enfatizado por um número restrito de estagiários.

Os resultados obtidos, relativamente, a concepções acerca do trabalho experimental parecem estar em concordância com o estudo realizado por Cachapuz, Malaquias, Martins, Thomaz e Vasconcelos (1989). Com efeito, a aplicação da teoria continuou a ser a finalidade de ensino associada à realização do trabalho experimental para a maioria dos estagiários enquanto que a investigação foi referida por um número diminuto de estagiários.

Este estudo mostra consistência entre pensamento e acção relativamente ao modo de estruturar o trabalho experimental, o que parece evidenciar a influência das concepções acerca do trabalho experimental no modo de o organizar. Com efeito, os estagiários que criticaram o trabalho experimental orientado para a descoberta (E5, E10, E12 e E14), usaram, nas aulas observadas, um guião experimental com procedimentos a serem seguidos, pelos alunos, de modo a possibilitar a verificação e aplicação da teoria. Pelo contrário, os estagiários (E3, E4 e E7) que valorizaram a investigação científica não usaram protocolo experimental para orientar as aprendizagens dos alunos. Deste modo, parece necessário que, em processos de aprendizagem do ensino, se identifiquem as concepções dos formandos acerca do trabalho experimental e se concebam estratégias que possam conduzir à mudança conceptual.

Este estudo revelou diferentes concepções acerca do trabalho experimental e vários modos de o organizar na sala de aula. De acordo com Cachapuz et al. (1989), “é importante encontrar um equilíbrio entre os diferentes tipos de trabalho experimental, favorecendo, nomeadamente, verificaçōes individuais e pequenas investigações, i.e., centrando o trabalho experimental preferencialmente nos alunos e perspectivandoo não simplesmente como ilustração de aspectos teóricos" (p. 69). Todavia, relativamente ao processo de aprendizagem vivenciado durante o estágio pedagógico algumas questões se colocam. Em que medida são equivalentes os diferentes modos usados pelos estagiários para organizar o trabalho experimental? Estaremos todos a pensar da mesma maneira quando falamos de trabalho experimental ou, pelo contrário, cada um de nós assume o significado partilhado (Jackson, 1992) sem nos darmos conta que estamos a atribuir diferentes significados? Num proces- 
so de aprender a ensinar importa reter que existem várias finalidades associadas ao uso do TE nas aulas de ciências: motivação dos alunos, desenvolvimento de competências manipulativas, sociais e científicas, aplicação da teoria, aquisição de técnicas, confronto de ideias e atribuição de novos significados que proporcionem aprendizagens diversificadas aos alunos dos ensinos básico e secundário.

\section{* Departemento de Educação, Faculdade de Ciências Universidade de Lisboa}

\section{REFERÊNCIAS}

Cachapuz, A., Malaquias, I., Martins, I. P., Thomaz, M. F., \& Vasconcelos, N. (1989). O trabalho experimental nas aulas de Física e Química. Gazeta de Fisica, 12(2), 65-69.

Clackson, S. G., \& Wright, D. K. (1992). An appraisal of practical work in science education. School Science Review, 74(266), 39-42

Clandinin, J. (1986). Classroom practice. Teachers images in action. London: The Falmer Press.

Doyle, W. (1990). Themes in teacher education research. In W. Houston (Ed.), Handbook of research on teacher education. New York, NY: Macmillan.

Driver, R. (1994). The fallacy of induction in science teaching. In R. Levinson (Ed.), Teaching science. London: Routledge.

Elbaz, F. (1983). Teacher thinking: A study of practical knowledge. New York, NY: Croom Helm.

Erickson, F. (1986). Qualitative methods in research on teaching. In M. C. Wittroch (Ed.), Handbook of research on teaching. New York, NY: Macmillan.

Freire, A. M. (1991). Contributo para uma tipologia de concepções de ensino de Física. Tese de mestrado não publicada. Universidade de Lisboa, Departamento de Educação da Faculdade de Ciências, Lisboa.

Guba, E. G., \& Lincoln, Y. S. (1994). Competing paradigms in qualitative research. In N. Denzin \& Y. S. Lincoln (Eds.), Handbook of qualitative research. Thousands Oaks, CA: Sage.

Hodson, D. (1992). Redefining and reorienting practical work in school science. School Science Review, 73(264), 65-78.

Hodson, D. (1993). Philosophic stance of secondary school science teachers, curriculum experiences, and children's understanding of science: some preliminary findings. Interchange, 24, 41-52.
Hodson, D. (1996a). Laboratory work as scientific method: Three decades of confusion and distortion. Journal of Curriculum Studies, 28(2), 115-135.

Hodson, D. (1996b). Practical work in school science: Exploring some directions for change. International Journal of Science Education, 18(7), 755-760.

Hodson, D. (1998). Teaching and learning science. Towards a personalized approach. Buckingham: Open University Press.

Hurd, P. (1969). New directions in teaching secondary school science. Chicago, IL: Rand McNally.

Jackson, P.W. (1992). Untaught lessons. New York, Ny: Teachers College Press.

Lazarowitz, R., \& Tamir, P. (1994). Research on using laboratory instruction in science. In D. L. Gabel (Ed.), Handbook of research on science teaching and learning. New York: Macmillan.

Lincoln, Y. S., \& Guba, E. G. (1985). Naturalistic inquiry. Newbury Park, CA: Sage.

Luneta, V. N. (1998). The school science laboratoty: Historical perspectives and contexts for contemporary teaching. In B. J. Fraser \& K. G. Tobin (Eds.), International handbook of science education. Dordrecht, Holanda: Kluwer Academic Press.

Marton, F., Dall'Alba, G., \& Beaty, E. (1993). Con- ceptions of learning. International Journal of Educational Research, 19(3), 277-300.

Olsen, T. P., Hewson, P. W., \& Lyons, L. (1996). Preordained science and student autonomy: The nature of laboratory tasks in physics classrooms. International Journal of Science Education, 18(7), 775-790.

Schwab, J.L. (1978). Education and the Structure of the disciplines. In I. Westbury \& N.J. Wilkof (Eds.), Science, curriculum and Liberal Education. Selected essays of Joseph L. Schwab. Chicago, II: the University of Chigago Press.

Solomon, J. (1994). The laboratory comes of age. In R. Levinson (Ed.), Teaching science. London: Routledge.

Strauss, A., \& Corbin, J. (1990). Basic of qualitative research. Grounded theory procedures and techniques. Newbury Park, CA: Sage.

Wellington, J. (1994). Secondary science. Contemporary issues and practical approaches. London: Routledge.

White, R. T. (1991). Episodes, and the purpose and conduct of practical work. In B. Woolnough (Ed.), Practical science. Milton Keynes: Open University Press.

White, R. T. (1996). The link between the laboratoty and learning. International Journal of Science Education, 18(7), 761-774.

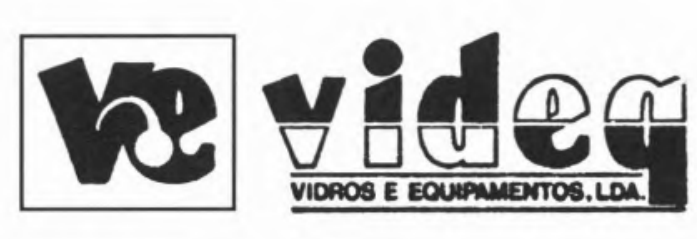

Equipamento de Laboratório

Balanças - Centrifugas - Aparelhos de $\mathrm{pH}$ - Tituladores Condutímetros - Agitadores - Espectrofotómetros Microscópios - etc.

Vidros e Plásticos de Laboratório Distribuidores NORMAX

\section{Material Didáctico}

Ensino Secundário e Superior

Representantes exclusivos SISTEDUC - Sistemas Educativos S.A.

Rua Soeiro Pereira Gomes, 15 r/c Frente
Bom Sucesso - 2615 Alverca

Telefs. (01) 95704 20/1/2 - Fax (351-1-957 04 23) - Portugal 

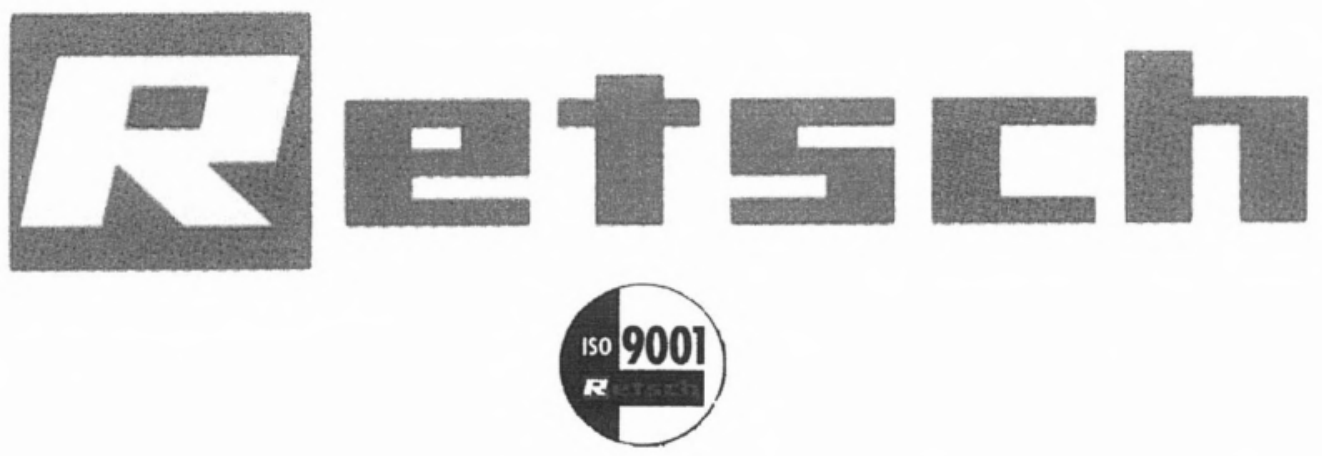

Moinhos
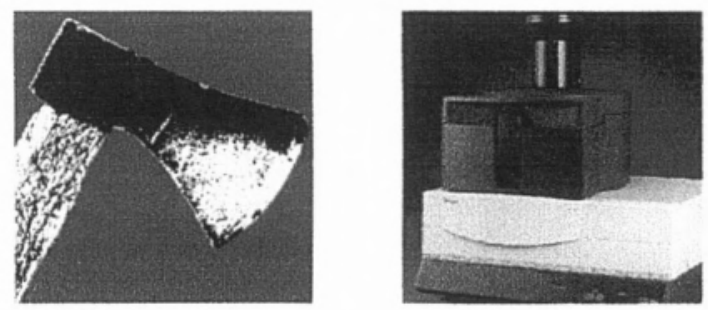

Agitadores de peneiros/peneiros
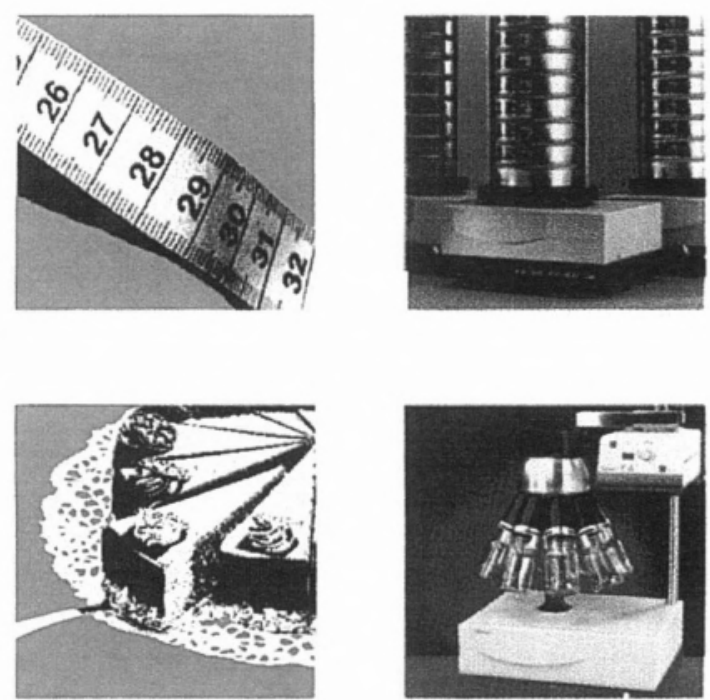

Divisores de amostras

Análise granulométrica automática CAMSIZER / CrYSTALSIZER

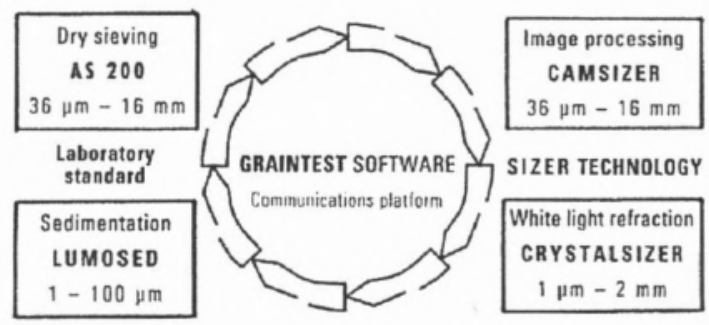

Peça-nos o contacto do agente mais próximo, através dos telefones: 01-352 7293 $02-9486868$

07 mpartadar Exclusiva 